\title{
Construction Process and Common Problems of Isolated Bearing
}

\author{
Han Zhang1, a , 'Xiaosheng Song1, b, Ying Zhang ${ }^{2, c}$ and Bo Dong ${ }^{1, d}$ \\ ${ }^{1}$ North China University of Science and Technology, Tangshan, Hebei, China \\ ${ }^{2}$ Beijing Jiaotong University, Beijing, China \\ a309081853@qq.com,b1034876396@qq.com,c1205935568@@qq.com,d919842954@qq.com
}

Keywords: Construction of Isolation Bearing, Construction of Isolation Building, Isolation Abstract. This paper mainly studies the characteristics of the construction technology of laminated rubber damping bearing and sliding isolated bearing, the common problems and solutions in the construction process, which provides reference for the construction of the relevant isolation bearing in the future.

\section{Introduction}

Seismic isolation technology is a new type of shock absorption and seismic method. The isolation building requires the installation of a seismic isolation device at the proper location of the building, which cuts off or weakens the transmission of the movement from the ground to the upper structure, and provides appropriate damping. Therefore, it will decrease seismic action of the upper structure and increase energy dissipation capacity. Currently, the promotion and application of seismic isolation technology are very fast in our country, but Determining how to install the isolation bearing to the isolation building reliably has become a key issue of the construction of isolation building [1]. The paper introduces the basic installation process and common problems of the isolation bearing, and provides reference for the construction of the isolation bearing.

\section{Common Construction Process of Isolation Bearing}

At present, in order to connect bearing body with lower buttress and upper buttress, upper and lower embedded parts, upper and lower anchorage steel, bolts and sleeves are necessary in the actual construction process. The specific construction drawings are as follows: Fig. 1 shows the construction of laminated rubber damping bearing and Fig. 2 shows the common construction process of isolation bearing.

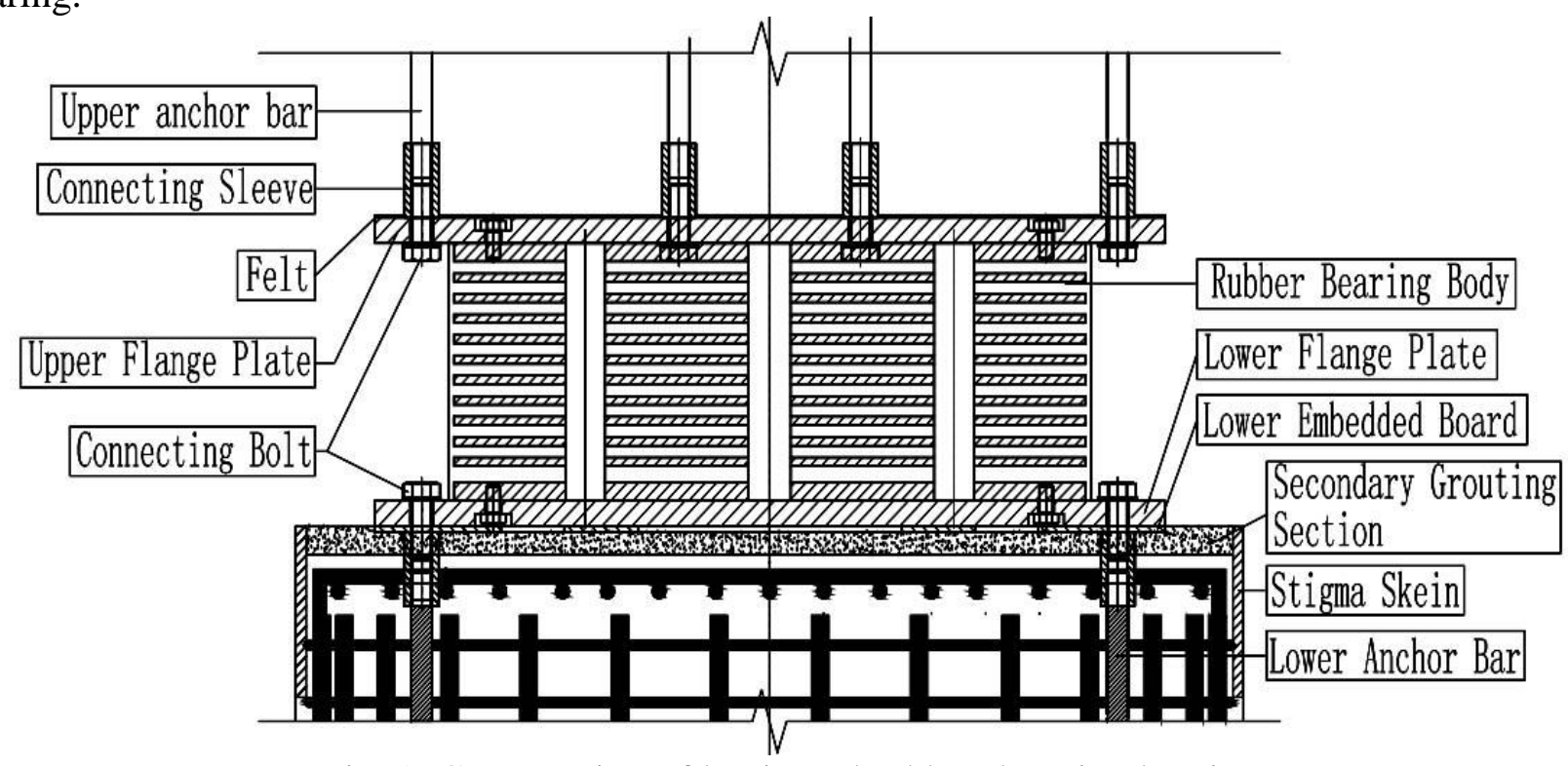

Fig. 1. Construction of laminated rubber damping bearing 


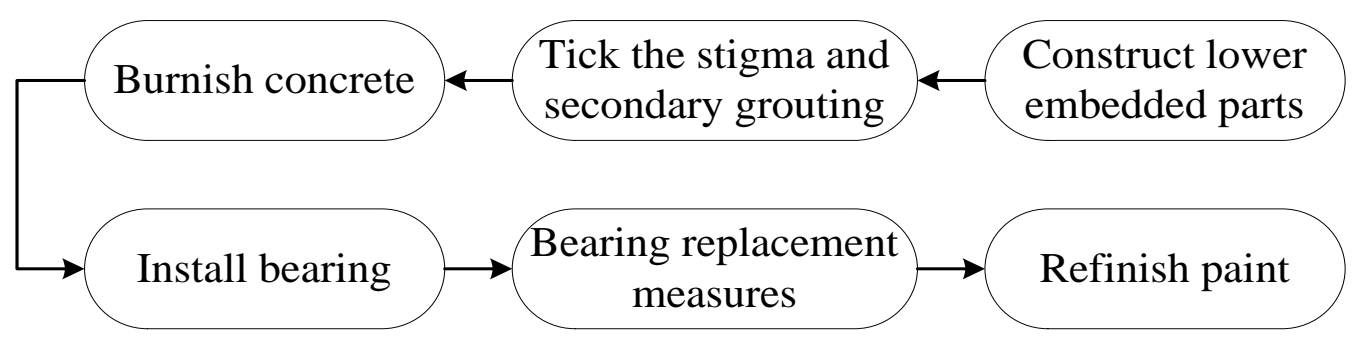

Fig. 2. Common Construction Process of Isolation Bearing

\section{Common Problems in the Construction of Isolation Bearing}

The Sleeve is not in Full Contact with the Embedded Board. The installation of the sleeve and the embedded board during the installation of the isolation bearing is a prerequisite for the installation of the bearing. Fig. 3 shows the installation of the sleeve. The relationship between the connecting sleeve and the embedded plate is vertical. By doing this, we can ensure that the sleeve is tightly fitted with the embedded board so as to be uniformly stressed by the connection of the bolt with the lower anchor bar, the lower embedded board and the bearing.

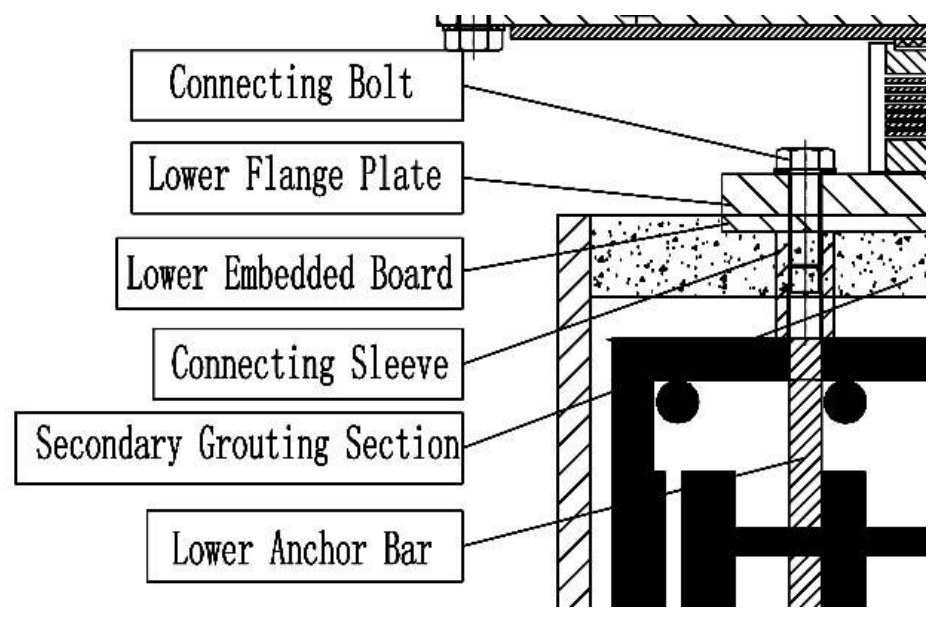

Fig. 3. The installation of the sleeve

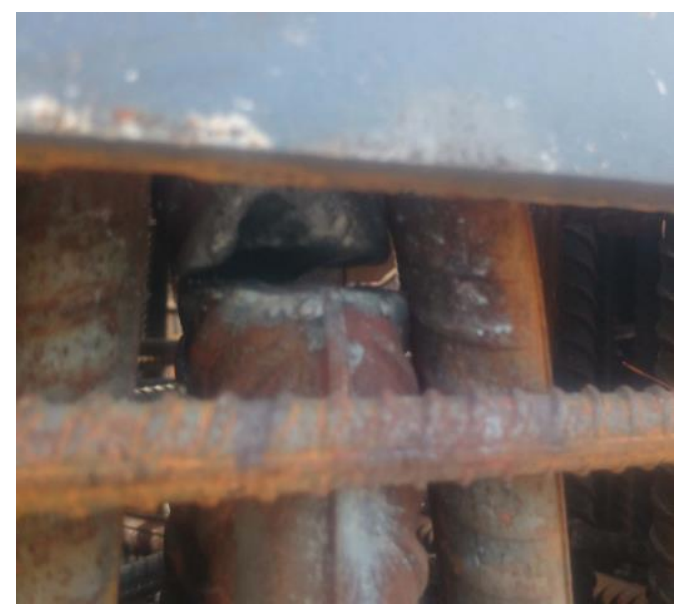

Fig. 4. The main reinforcement is cut

Problems of Cutting Column Gluten. The steel bar in the part of the column pier is too dense in some projects, and there is column gluten, column pier gluten, sheet-beam and beam bar which are crisscrossed together. The upper and lower anchor bars of the bearing may conflict with the bars of the column during the installation. Due to management problems, the phenomenon that the steel bar or even the main reinforcement of the beam-column is cut will appear in the part of the project. Fig. 4 shows that the main reinforcement is cut. If the reinforcement is too dense, the main reinforcement lap can be replaced by straight thread connection which helps avoid the disadvantage of too much main reinforcement [2].

Reliability of Stigma Secondary Grouting. In order to strengthen the stigma, the stigma will be given secondary grouting in some projects. Due to the thickness of the grouting is limited, the grouting material has been filled with the embedded board resulting from non-dense vibrating and the embedded board is hollowing after the concrete is solidified in the process of secondary grouting. Fig. 5 shows the hollowing problem of the embedded board. There are two main reasons for this phenomenon. The first one is that the stigma skein is too low that the grouting material is higher than the template and spills over it. The second one is non-dense vibrating. To solve this problem, the grouting material which slightly expands can be used and the stigma secondary grouting material must be fully vibrated. 


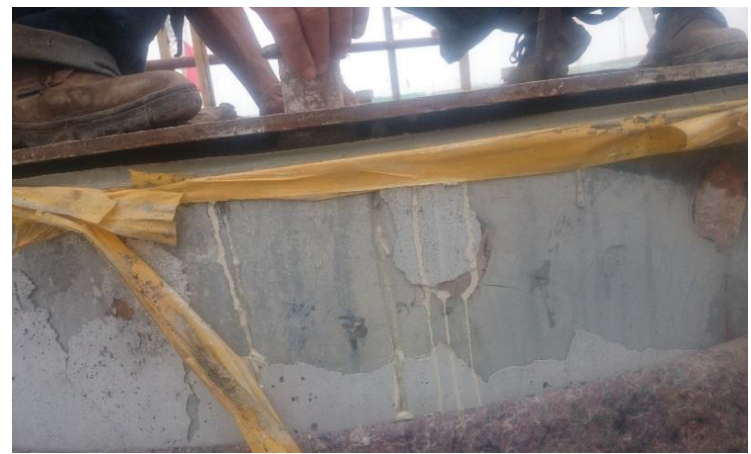

Fig. 5. The hollowing problem of the embedded board

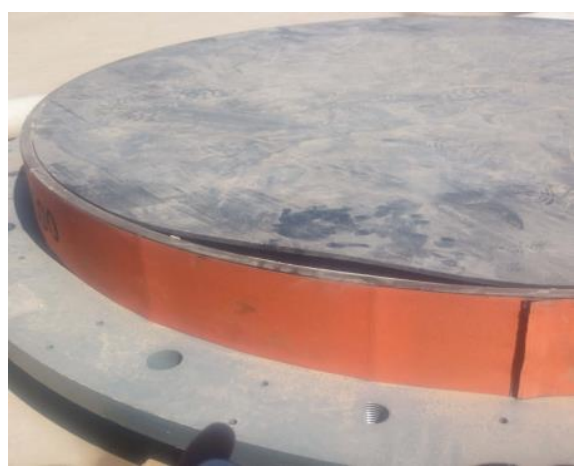

Fig. 6. The PTFE isolation bearing exposed to the sun is degummed and with bulge

Storage of Isolation Bearings. Proper protective measures must be taken for isolation bearings and their connections after entering into the site and being accepted. What we need to pay special attention to is that isolation bearings and their connections cannot be with the acidic and non-polar solvent. In addition, instead of being exposed to the sunlight, the isolation bearing should be stored in a cool dry warehouse, sealed and protected from light. Meanwhile, isolation bearings should be stacked according to the number of buildings if there are many buildings using isolation bearings in the same project [3].

Isolation bearings are treated with improper storage after entering into the site and being accepted. Fig. 6 shows the phenomenon that the PTFE isolation bearing exposed to the sun is degummed and with bulge. Fig. 7 shows that storage location and other issues lead to the corrosion of the bearing in the preparation process of the construction materials. Fig. 8 shows that PTFE is contaminated in preparation for the installation process of the isolation bearing. And Fig. 9 shows that the sliding isolated bearing is inverted in the preparation process of the construction.

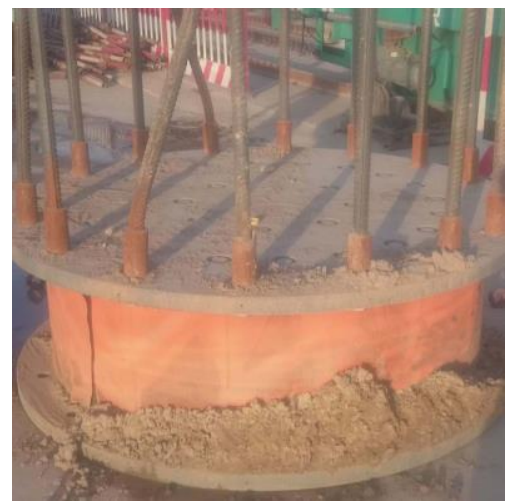

Fig. 7. Storage location and other issues lead to the corrosion of the bearing

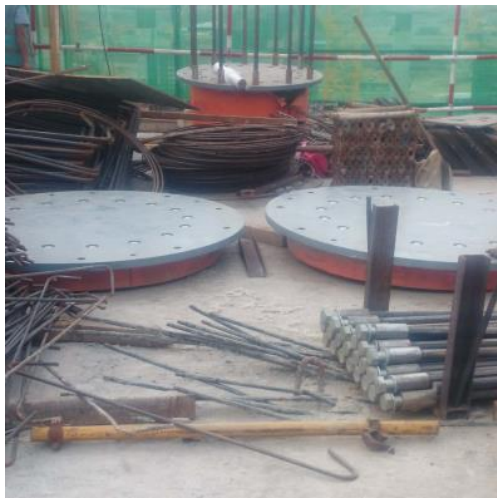

Fig. 9. The sliding isolated bearing is inverted

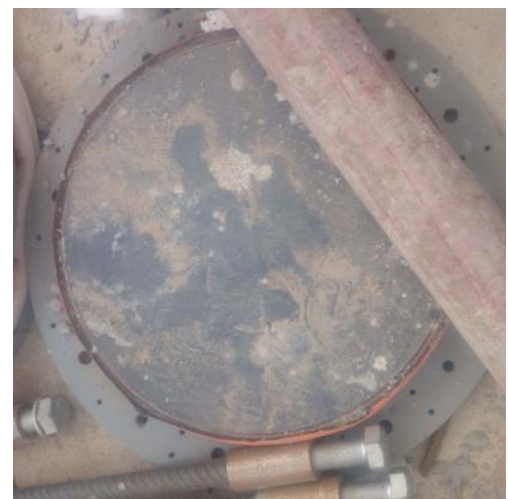

Fig. 8. PTFE is contaminated

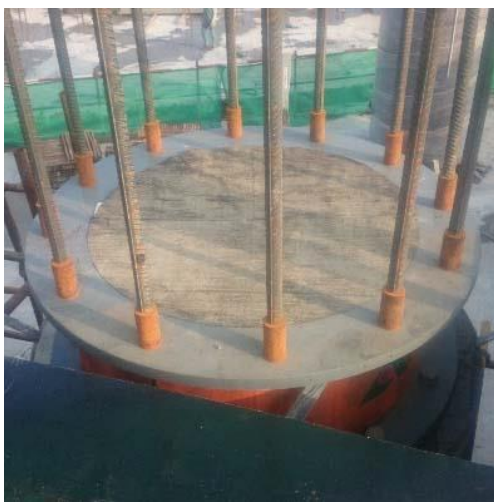

Fig. 10. The size of the felt is too small

Bearing Replacement in Later Period. In order to facilitate the replacement of the isolation bearing in the future, the SBS felt, 3mm thick, shall be laid on the upper surface of the flange plate, 
and the felt shall be cut and perforated according to the sleeve position and the same size as the flange plate. The felt should be laid flat. The situation that there is not a felt matched with a flange plate, the size of the felt is less than that of the flange plate of the bearing, or the felt has broken holes should be avoided. Fig. 10 shows that the size of the felt is too small.

Installation of Mirror Board of the Sliding Bearing. In order to make full use of the space of the isolation layer, it is a common practice to set up an isolation layer under the roof of the basement whose sliding isolated bearing is composed of mirror board and PTFE bearing body and the area of the mirror board is much larger than that of the bearing body. Therefore, placing the mirror board of the bearing on the bearing body to ensure the use of the lower space is a usual practice. Fig. 11 shows that the placement of the sliding isolation bearing.

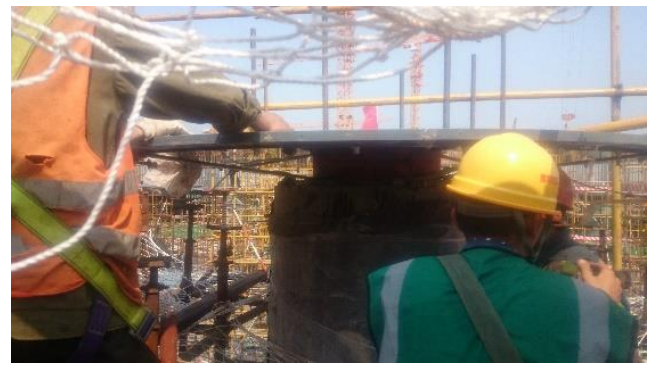

Fig.11. The placement of the sliding isolation bearing

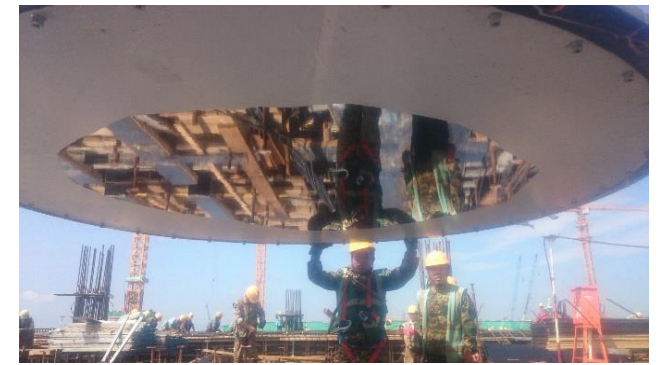

Fig. 12. Uncover the upper flange plate of the protective film during installation

Installation of Upper Cover of the Sliding Isolation Bearing. We are expected to use prefabricated hoisting holes in the process of the lifting process of the upper cover of the sliding isolation bearing and there must be 4 or more hanging points which ensures that the mirror board remains horizontal in the lifting and is protected from any bumps. Uncover the protective film on the mirror board under the upper cover. The size of the protective film uncovered is the same as the diameter of the bearing body, and the rest is removed after the pouring of the upper buttress is finished which avoids contaminating the mirror board in the pouring process of the upper structure. Fig. 12 shows the process of uncover the upper flange plate of the protective film during installation.

Fixation of Upper Cover of the Sliding Isolation Bearing. If the flange plate with a mirror plate is on the upper part of the sliding isolation bearing body, it would be called the upper cover of the sliding bearing. The size of the upper cover of the sliding bearing is much larger than that of the isolation bearing body, so the upper cover of the sliding bearing may move or overturn due to the stampede from installers, the installation of the upper buttress template, the grouting, the vibrating, etc., in the pouring process of the upper buttress. Taking what we have discussed above into consideration, there are two specific measures. The first one is to use connection bars to connect the lower and upper flange plates of the sliding isolation bearing. Fig. 13 shows the connection bars. The second one is to use the scaffold around the pillars to support the upper cover of the sliding isolation bearing. But pay attention to add square wood when contacting with the mirror panel of the upper cover to prevent the scaffold from scratching the mirror panel. Fig. 14 shows the upper cover of the sliding isolation supported by the scaffold.

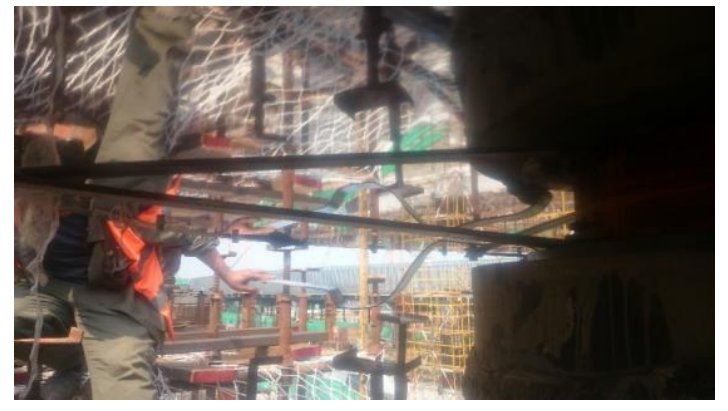

Fig. 13. The connection bars

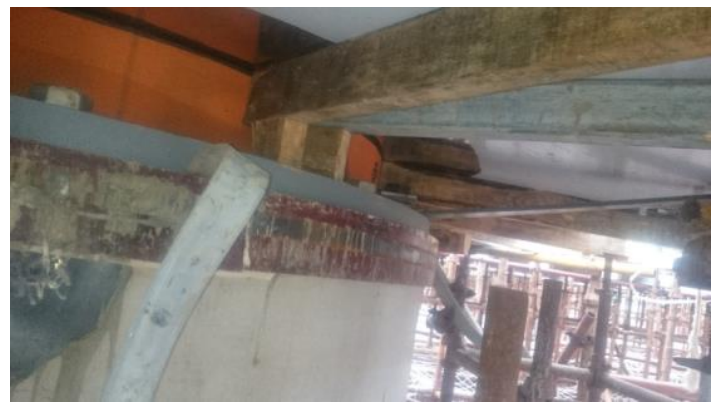

Fig. 14. The upper cover of the sliding isolation supported by the scaffold 


\section{Conclusions}

In this paper, we have discussed the common problems which need to be attached great importance to during the installation and construction of the isolation bearing, and provided relevant and feasible solutions as references for the installers. With the relevant industry standards and local standards promulgated and implemented, the installation and construction of isolation bearings become more standard. Under these circumstances, construction workers are expected to abide by the construction acceptance criteria, contact with the actual project and constantly update the related construction method of isolated bearing installation to ensure the construction quality of isolated bearing installation.

\section{References}

[1] Xupeng Yin, Wen Pan, Longfei Zhang: Low Temperature Architecture Technology. Vol. 06 (2013), P. 46 (In Chinese)

[2] Dali Jiang: Architecture Technology. Vol. 38 (2007), P. 94 (In Chinese)

[3] Xiaorong Chen: Quality Management. Vol.32 (2014), P. 13 (In Chinese)

[4] Zhou X Y, Han M, Yang L: Implementation and Application of Automata. Vol. 4783 (2007), P. 253

[5] Islam. A, Jameel. M, Jumaat. M Z: Journal of Engineering \& Technology Research. Vol. 03 (2011), P. 99 